p-ISSN 1412-3770 e-ISSN 2540-9840

Accredited by Ministry of Research, Technology

and Higher Education No: 28/E/KPT/2019
Jurnal Ilmiah Sains, Oktober 2020, 20(2):100-105

DOI: https://doi.org/10.35799/jis.20.2.2020.28631

Available online at https://ejournal.unsrat.ac.id/index.php/jis

\title{
Penentuan Harga Premium Asuransi Tanaman Sagu di Kabupaten Luwu Menggunakan Copula FGM
}

\author{
Apriyanto Apriyanto ${ }^{* *}$ \\ ${ }^{1)}$ Program Studi Teknik Informatika, Universitas Andi Djemma, Palopo, Sulawesi Selatan \\ *corresponding author: apriyanto.mtk@unanda.ac.id
}

(Article History: Received 25-05-2020; Accepted 21-08-2020; Published 22-08-2020)

\begin{abstract}
ABSTRAK
Fokus utama penelitian ini adalah menghitung harga premium asuransi menggunakan Copula FGM. Adapun tujuan utama dari penelitian ini yaitu menentukan harga premium asuransi yang ideal untuk tanaman Sagu di Kabupaten Luwu. Penelitian ini merupakan penelitian terapan (applied approach) dengan menggunakan data kuantitatif untuk luas lahan dan hasil produksi Sagu di Kabupaten Luwu yang bersumber dari data Badan Pusat Statistik (BPS). Tahapan-tahapan yang dilakukan dalam penelitian ini dimulai dengan melakukan studi kepustakaan untuk mengkaji konsep dasar Copula dan konsep Copula FGM beserta sifat-sifatnya; mengumpulkan data kuantitatif luas lahan (X) dan hasil produksi Sagu (Y); mengukur dependensi antara luas lahan dan hasil produksi Sagu menggunakan Copula FGM; dan terakhir menentukan harga premium asuransi pertanian (crop insurance) yang ideal. Hasil yang diperoleh dari penelitian ini yaitu: (1) Harga premium yang ideal berada pada kisaran harga Rp. 24.000 - Rp. 60.000 per Ha; (2) Harga premium asuransi yang ideal untuk tanaman Sagu di Kabupaten Luwu sangat bergantung pada besarnya deductible; dan (3) Harga premium untuk deductible dengan range kecil menghasilkan harga yang relatif lebih murah dibandingkan range deductible yang besar.
\end{abstract}

Kata kunci: Copula FGM; Crop Insurance; Premium Asuransi; Sagu.

\section{Determination of Insurance Premium Price for Sago Plant in Luwu Regency Using FGM Copulas}

\begin{abstract}
The main focus of this study is to calculate the price of insurance premiums using FGM Copulas. The main objective of this research is to determine the ideal prices of insurance premium for Sago plants in Luwu Regency. This research is an applied approach using quantitative data for land area and Sago production in Luwu Regency sourced from the Central Statistics Agency Data. The stages carried out in this study began by conducting a literature study to examine the basic concepts of Copulas, the concept of FGM Copulas and their properties; collect quantitative data on land area (X) and Sago Production (Y); measure dependencies between land area and Sago production using the FGM Copulas; and finally determine the ideal price of insurance premium for Sago plants. The results of this study are: (1) The ideal premium is in the range of IDR 24,000 to IDR 60,000 per Ha; (2) The ideal premium for Sago plant in Luwu Regency is very dependent on amount of the deductible; (3) The premium for deductibles with small range relatively lower than large range.
\end{abstract}

Keywords: FGM Copulas; Crop Insurance; Insurance Premiums; Sago.

\section{PENDAHULUAN}

Salah satu sektor yang memiliki peran penting pada perekonomian dan mampu memberikan dampak pada sektor lainnya di Indonesia adalah sektor Pertanian (Zamzany \& Setiawan, 2018). Pada Buku Statistik
Indonesia dalam Infografis tahun 2017 diketahui bahwa pada tahun 2016 dari 258,7 juta jiwa populasi Indonesia terdapat 31,9\% penduduk usia kerja yang bekerja pada sektor-sektor seperti Kehutanan, Perikanan, dan Pertanian (Badan Pusat Statistik, 2017). Angka ini menunjukkan bahwa hampir 
separuh populasi penduduk Indonesia bergantung hidup pada sektor Pertanian yang sebenarnya tidak lepas dari ketidakpastian. Ancaman seperti gagal panen, penurunan hasil produksi pertanian, maupun perubahan harga komoditas yang diakibatkan oleh perubahan iklim (kemarau atau banjir), serangan penyakit dan hama tanaman, atau terjadinya bencana alam menjadi risiko tersendiri yang harus dihadapi oleh para petani (Asmara et al., 2019). Oleh karena itu, risiko-risiko yang mengancam para petani harus dapat diminimalisir, salah satunya dengan memberikan perlindungan jaminan berupa asuransi pertanian (crop insurance).

Namun, penentuan harga premium asuransi pertanian yang ideal masih menjadi masalah yang harus dipecahkan. Padahal jika dilihat dari faktor risiko maka sektor pertanian nyatanya memiliki risiko yang besar mengalami kerugian (loss). Oleh karena itu, dalam memodelkan harga premium asuransi pertanian maka faktor loss sangat penting untuk diperhatikan. Dalam teori Aktuaria tradisional, setiap individu diasumsikan independent. Namun, pada kenyataannya diketahui bahwa masingmasing individu memiliki dependensi satu sama lain. Dependensi masing-masing individu tersebut dapat diukur menggunakan korelasi, regresi, atau copula. Konsep copula telah banyak digunakan dalam bidang Matematika, Statistika, Keuangan, maupun Aktuaria dalam menghitung nilai risiko. Secara sederhana, konsep copula dapat digunakan memodelkan struktur dependensi data yang tidak memenuhi sifat-sifat distribusi normal (Pintari \& Subekti, 2018). Oleh karena itu, konsep ini cocok digunakan dalam menentukan harga premium asuransi karena sering dijumpai data loss tidak mengikuti distibusi normal.

Kata copula pertama kali diperkenalkan dalam ilmu Matematika atau Statistika oleh Abe Sklar. Selanjutnya, konsep copula dalam konteks asuransi diperkenalkan untuk pertama kali oleh Wang pada tahun 1998 (Amblard \& Girard, 2009). Menurut Fisher (1997), ada dua alasan mengapa copula menarik perhatian Statistikawan yaitu: (1) konsep copula dapat digunakan untuk mempelajari ukuran dependensi dalam skala yang bebas; dan (2) konsep copula merupakan titik awal untuk menyusun keluarga-keluarga distribusi bivariat. Sedangkan menurut Nelsen (2006) sendiri, konsep copula pada dasarnya merupakan fungsi gabungan atau couple fungsi distribusi marginal univariat menjadi fungsi distribusi multivariat. Berkaitan dengan hal tersebut, konsep copula dapat digunakan dalam menggabungkan distribusi marginal antara luas lahan sagu dengan hasil produksi.

Selain Papua dan Sumatera, pulau Sulawesi juga menjadi penghasil Sagu terbesar di Indonesia. Salah satu provinsi di Sulawesi yang banyak menghasilkan Sagu adalah Provinsi Sulawesi Selatan. Sebagai salah satu Kabupaten besar di Sulawesi Selatan, Kabupaten Luwu yang berjarak sekitar $300 \mathrm{~km}$ dari Kota Makassar dengan luas wilayah administrasi kurang-lebih $3.000,25 \mathrm{~km}^{2}$, terdiri dari 22 kecamatan dan 227 desa/kelurahan, menempatkan Sagu pada urutan kelima setelah Cengkeh, Coklat, Kelapa Dalam, dan Kelapa Hibrida sebagai jenis tanaman yang memiliki areal perkebunan terluas (BPS Kab. Luwu, 2019). Oleh karena itu, penelitian ini bertujuan untuk menentukan harga premium asuransi yang ideal untuk tanaman Sagu yang dapat dijadikan opsi bagi pemerintah daerah dalam memberikan perlindungan kepada para petani Sagu di Kabupaten Luwu.

\section{METODE PENELITIAN}

Penelitian ini dilaksanakan pada bulan Januari sampai Maret 2020 dengan mengambil data sekunder terkait luas lahan dan hasil produksi Sagu terakhir dari Badan Pusat Statistik Kabupaten Luwu. Penelitian ini menggunakan data sekunder karena keterbatasan peneliti mengunjungi lokasi perkebunan Sagu selama masa pandemik Covid-19. Jenis penelitian ini adalah penelitian terapan (applied approach) (Multyaningsih \& Nuryanto, 2014). Data yang digunakan adalah data kuantitatif berupa luas lahan (areal) yang ditanami Sagu (Ha) dan hasil produksi Sagu (Ton).

Langkah-langkah yang dilakukan dalam penelitian ini yaitu: (1) mendefinisikan copula FGM dan sifat-sifatnya; (2) mengumpulkan dan menginterpretasikan data luas lahan dan hasil produksi Sagu pada tahun 2018 di Kabupaten Luwu; (3) menguji kecocokan copula (goodness of fit); (4) menentukan besaran loss dan frekuensi 
kedatangan klaim; dan (5) menentukan harga premium asuransi menggunakan Copula FGM dengan membatasi besaran klaim (deductible).

\section{HASIL DAN PEMBAHASAN}

\section{Copula Farlie-Gumble-Morgenstern}

Copula Farlie-Gumble-Morgenstern (Copula FGM) merupakan jenis copula yang banyak digunakan dalam memodelkan risiko. Copula FGM didefinisikan sebagai berikut.

Definisi 1: Diberikan sebarang pasangan variabel random $(\mathrm{X}, \mathrm{Y})$ dengan fungsi marginal $\mathrm{F}(\mathrm{x})$ dan $\mathrm{H}(\mathrm{y})$, maka dapat dibentuk fungsi distribusi gabungan $\mathrm{G}(\mathrm{x}, \mathrm{y})$ dengan:

$$
\begin{gathered}
G(x, y)=F(x) H(y)[1+\theta(1-F(x))(1- \\
H(y))], \text { untuk }-1 \leq \theta \leq 1
\end{gathered}
$$

Sehingga untuk setiap $\mathrm{u}, \mathrm{v}$ di I diperoleh,

$$
\begin{gathered}
C_{\theta}(u, v)=u v[1+\theta(1-u)(1-v)], \text { untuk } \\
-1 \leq \theta \leq 1
\end{gathered}
$$

Fungsi $C_{\theta}(u, v)$ tersebut dinamakan dengan Copula FGM. Adapun probability density function (pdf) yang diperoleh dari Copula $F G M$ di atas dapat dipertegas oleh teorema berikut ini.

Teorema 1: Probability density function (pdf) dari Copula FGM dapat ditulis dengan,

$$
\begin{gathered}
c(u, v)=1+\theta(1-2 u)(1-2 v), \\
-1 \leq \theta \leq 1
\end{gathered}
$$

Selain memodelkan risiko, Copula FGM juga banyak digeneralisasi untuk memperluas range dari nilai korelasinya (Bekrizadeh et al., 2012). Salah satu pendekatan alternatif yang dapat digunakan untuk memperoleh generalisasi dari copula parametrik adalah dengan melakukan transformasi menjadi copula semiparametrik (Amblard \& Girard, 2009). Khusus untuk Copula FGM bentuk semiparametrik didefinisikan sebagai berikut: Definisi 2: Diberikan fungsi yang didefinisikan pada $\mathbb{I}^{2}$ yaitu,

$$
C_{\theta}^{S P}(u, v)=u v+\theta \phi(u) \phi(v)
$$

dengan $(u, v) \in \mathbb{I}^{2}$ dan $\theta \in[-1,1]$

Jika dipilih $\phi(x)=x^{3}$, maka diperoleh nilai rho Spearman berada pada interval $\left[-\frac{3}{4}, \frac{3}{4}\right]$. Hal ini diperjelas oleh teorema berikut.

Teorema 2: Diberikan pasangan variabel random $(\mathrm{X}, \mathrm{Y})$ dan copula semiparametrik $C_{\theta}^{S P}(u, v)$. Bentuk rho Spearman dari copula tersebut dapat ditulis dengan,

$$
\rho_{\theta}^{S P}=12 \theta \Phi^{2}(1)
$$

dengan $\Phi(1)=\int_{0}^{1} \phi(t) d t$

Berdasarkan bentuk semiparametrik di atas, maka dapat didefinisikan generalisasi Copula FGM adalah sebagai berikut (Amblard \& Girard, 2009).

Definisi 3: Diberikan fungsi yang terdefinisi pada $\mathbb{I}^{2}$ yaitu:

$$
C_{\theta, \phi}(u, v)=u v+\theta(\max (u, v)) \phi(u) \phi(v)
$$

dengan $\phi$ dan $\theta$ adalah fungsi differensiable kontinu $\mathbb{I} \rightarrow \mathbb{R}$.

Jika $\phi$ dan $\theta$ adalah fungsi null pada II maka $C_{\theta, \phi}=\Pi$. Selanjutnya, diasumsikan $\theta$ bukan fungsi nol pada II dan $\phi$ bernilai nol di titik isolasi II. Untuk menjamin $C_{\theta, \phi}$ adalah copula diberikan syarat perlu dan cukup untuk $\phi$ dan $\theta$ pada teorema berikut.

Teorema 3: Diberikan $C_{\theta, \phi}$ adalah copula jika dan hanya jika $\phi$ dan $\theta$ memenuhi kondisi-kondisi berikut:

$$
\begin{gathered}
\phi(0)=0 \\
\phi(1) \phi(1)=0
\end{gathered}
$$

$\phi^{\prime}(u)(\theta \phi)^{\prime}(v) \geq-1$ untuk setiap $0<u<$ $v<1$ dan $\theta^{\prime}(u) \leq 0$ untuk setiap $u \in(0,1)$. dengan memperhatikan definisi $C_{\theta, \phi}$ maka dapat diperoleh probability density function (pdf) yang dijabarkan pada teorema berikut.

Teorema 4: Diberikan pasangan variabel random $(\mathrm{X}, \mathrm{Y})$ dan copula $C_{\theta, \phi}$ maka pdf dari copula tersebut ditulis dengan,

$$
\begin{aligned}
& c_{\theta, \phi}(u, v) \\
& =1+(\theta \phi)^{\prime}(\max (u, v)) \phi^{\prime}(\min (u, v))
\end{aligned}
$$

\section{Data Tanaman Sagu}

Berdasarkan data Badan Pusat Statistik Kabupaten Luwu, data luas lahan (areal) yang ditanami Sagu (Ha) dan hasil produksi (Ton) tahun 2018 telihat pada Tabel 1. Dari tabel 1 diketahui bahwa luas seluruh lahan yang ditanami Sagu adalah 1334,9 Ha dengan hasil produksi sebanyak 881,2 Ton. Dari 22 kecamatan terdapat dua kecamatan yang sama sekali tidak ditanami tanaman Sagu yaitu Kecamatan Bassesangtempe dan Bassesangtempe Utara, terdapat pula tiga kecamatan yang luasnya di atas $100 \mathrm{Ha}$, sehingga pada perhitungan harga premium tidak digunakan rata-rata melainkan median dari data. Adapun median dan simpangan baku masing-masing yaitu $\operatorname{Me}(X)=54,8$; $\sigma_{\mathrm{X}}=75,5 ; \operatorname{Me}(Y)=35,5 ;$ dan $\sigma_{\mathrm{Y}}=48,7$. Dari data tersebut juga diketahui bahwa meskipun lahan Sagu pada Kecamatan Ponrang lebih luas, tapi hasil produksinya 
masih kalah dibandingkan dibandingkan Kecamatan Bajo.

Tabel 1. Data Luas Lahan dan Hasil Sagu Kabupaten Luwu

\begin{tabular}{|c|c|c|c|}
\hline No. & $\begin{array}{c}\text { Nama } \\
\text { Kecamatan }\end{array}$ & $\begin{array}{l}\text { Luas } \\
\text { Lahan } \\
\text { (Ha) }\end{array}$ & $\begin{array}{l}\text { Hasil } \\
\text { Produksi } \\
\text { (Ton) }\end{array}$ \\
\hline 1 & Larompong & 77,8 & 47 \\
\hline 2 & $\begin{array}{l}\text { Larompong } \\
\text { Selatan }\end{array}$ & 70,8 & 50 \\
\hline 3 & Suli & 78 & 55 \\
\hline 4 & Suli Barat & 55,5 & 44 \\
\hline 5 & Belopa & 56 & 46 \\
\hline 6 & Kamanre & 2 & 1,6 \\
\hline 7 & Belopa Utara & 7,5 & 6,6 \\
\hline 8 & Bajo & 104,5 & 72 \\
\hline 9 & Bajo Barat & 96 & 62 \\
\hline 10 & Bassesangtempe & 0 & 0 \\
\hline 11 & Latimojong & 8 & 5 \\
\hline 12 & $\begin{array}{l}\text { Bassesangtempe } \\
\text { Utara }\end{array}$ & 0 & 0 \\
\hline 13 & Bupon & 54 & 40 \\
\hline 14 & Ponrang & 119 & 65 \\
\hline 15 & Ponrang Selatan & 23,8 & 19 \\
\hline 16 & Bua & 58,5 & 46 \\
\hline 17 & Walenrang & 12,5 & 7 \\
\hline 18 & $\begin{array}{l}\text { Walenrang } \\
\text { Timur }\end{array}$ & 45 & 20 \\
\hline 19 & Lamasi & 60 & 31 \\
\hline 20 & Walenrang Utara & 358,5 & 232 \\
\hline 21 & Walenrang Barat & 7 & 5 \\
\hline 22 & Lamasi Timur & 40,5 & 27 \\
\hline
\end{tabular}

\section{Distribusi Data}

Pada penelitian ini, digunakan aplikasi EasyFit versi 5.6 yang dikembangkan oleh MathWave Technologies, Ukraina untuk menentukan distribusi masing-masing variable random (X dan $\mathrm{Y}$ ). Hasil $P-P$ Plot dari masing-masing $\mathrm{X}$ dan $\mathrm{Y}$ disajikan pada gambar berikut.

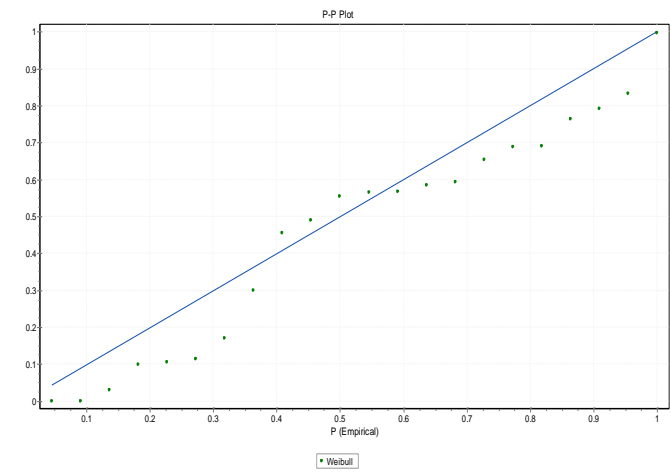

Gambar 1. Hasil P-P Plot untuk Luas Lahan Tanaman Sagu

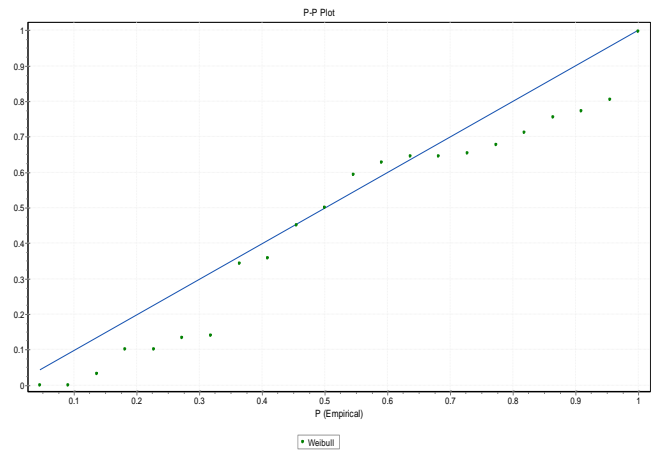

Gambar 2. Hasil P-P Plot untuk Hasil Produksi Sagu

Berdasarkan Gambar 1 dan Gambar 2, terlihat bahwa titik-titik ploting tidak selalu mengikuti dan mendekati garis diagonalnya. Oleh karena itu, dapat disimpulkan bahwa nilai residual tidak berdistribusi normal. Berdasarkan hasil pengujian menggunakan EasyFit, diketahui bahwa masing-masing data luas lahan dan hasil produksi menunjukkan grafik yang mengikuti distribusi Weibull. Setiap parameter pada distribusi Weibull diestimasi menggunakan metode Maximum Likelihood Estimator (MLE) (Myung, 2003). Diperoleh nilai parameter alpha dan theta untuk variable random X yaitu $\alpha=1,0007$ dan $\theta=66,767$ sehingga Cumulative Distribution Function (CDF) menjadi:

$$
F(x)=1-e^{-\left(\frac{x}{66,767}\right)^{1,0007}}
$$

Sedangkan nilai estimasi untuk parameter-parameter variable random $\mathrm{Y}$ yaitu $\alpha=1,0223$ dan $\theta=44,485$ sehingga diperoleh CDF untuk Y yaitu:

$$
H(y)=1-e^{-\left(\frac{y}{44,485}\right)^{1,0223}}
$$

\section{Uji Kecocokan Copula}


Jika dimisalkan $F(x)=u \quad$ dan $H(x)=v$ maka diperoleh pasangan $(u, v)$, sehingga nilai copula empirik untuk masingmasing pasangan data $(u, v)$ dinotasikan dengan $C_{n}(u, v)$. Goodness of Fit Copula ini menggunakan Root Mean Square Error (RMSE) dengan membandingkan antara nilai copula empirik dan copula teoritikal dengan menggunakan rumus berikut.

$R M S E=\sqrt{\frac{1}{n} \sum_{i=1}^{n}\left(C\left(u_{i}, v_{i}\right)-C_{n}\left(u_{i}, v_{i}\right)\right)^{2}}$ dengan $n$ adalah anyaknya pasangan data, $C_{n}\left(u_{i}, v_{i}\right)$ adalah Copula empirik, dan $C\left(u_{i}, v_{i}\right)$ adalah Copula teoritikal. Diperoleh perbandingan nilai antara Copula FGM, Copula Clayton, dan Copula Gumble sebagai berikut.

Tabel 2. Nilai RMSE

\begin{tabular}{cccc}
\hline & FGM & Clayton & Gumbel \\
\hline Error & 0,397 & 0,364 & 0,360 \\
\hline
\end{tabular}

Dari tabel 2 dapat dilihat bahwa nilai error ketiga copula hampir sama yaitu berada di sekitar 0,3. Hal ini menunjukkan bahwa Copula FGM juga sangat cocok digunakan dalam memodelkan harga premium asuransi khususnya asuransi untuk tanaman Sagu di Kabupaten Luwu.

\section{Harga Premium Asuransi Menggunakan Copula FGM}

Harga premium asuransi diperoleh dari rata-rata keseluruhan nilai sekarang pembayaran klaim per hektar. Nilai tersebut dihitung dari besaran loss, besaran klaim, frekuensi klaim, dan waktu kedatangan klaim. Besaran loss dihitung dari rata-rata selisih antara hasil produksi dari data dengan hasil produksi Sagu yang seharusnya yaitu sekitar 1 ton tepung sagu basah tiap Ha. Sehingga, diperoleh nilai besaran loss hasil produksi Sagu di Kabupaten Luwu yaitu 22,7. Besar klaim dihitung menggunakan rumus:

\footnotetext{
Besar Klaim = Harga per kg x $100 \times$ loss

Dengan harga yang digunakan yaitu $\mathrm{Rp}$. 3.500 per kg.

Dari besarnya klaim yang diperoleh berdasarkan perhitungan di atas maka diperoleh besarnya pembayaran klaim per
}

loss (PL) dengan menggunakan formula berikut untuk polis yang menggunakan deductible (d)

$$
P^{L}=\left\{\begin{array}{cc}
0 & ; j i k a L \leq d_{b} \\
L-d_{b} & ; j i k a d_{b}<L<d_{a} \\
d_{a} & ; j i k a L \geq d_{a}
\end{array}\right.
$$

dengan $L$ adalah besar klaim, $d_{b}$ adalah deductible bawah dan $d_{a}$ adalah deductible atas.

Selanjutnya, ditentukan nilai dari variabel random waktu kedatangan klaim. Karena banyaknya klaim dimodelkan dengan menggunakan proses Poisson dengan intensitas kedatangan klaim adalah $\lambda$. Oleh karena itu, frekuensi klaim diasumsikan berdistribusi Poisson dengan parameter $\lambda$. Sedangkan waktu kedatangan klaim diasumsikan mengikuti distribusi eksponensial dengan mean $\frac{1}{\lambda}$. Dari data frekuensi klaim diperoleh estimasi parameter dengan menggunakan MLE nilai

$$
\lambda=\sum_{i=1}^{n} \frac{x_{i}}{n}
$$

diperoleh yaitu 10. Sehingga, harga premium asuransi pertanian dengan menggunakan Copula FGM disajikan pada tabel 3.

Tabel 3. Harga Premium Asuransi

\begin{tabular}{cccc}
\hline No. & $d_{b}(\mathrm{Rp})$. & $d_{a}(\mathrm{Rp})$. & $\begin{array}{c}\mathrm{Harga} / \mathrm{Ha} \\
(\mathrm{Rp} .)\end{array}$ \\
\hline 1. & 0 & 3.000 .000 & 24.700 \\
2. & 0 & 10.000 .000 & 57.500 \\
3. & 0 & 7.000 .000 & 48.000 \\
4. & 3.000 .000 & 7.000 .000 & 36.000 \\
5. & 3.000 .000 & 10.000 .000 & 32.500 \\
6. & 7.000 .000 & 10.000 .000 & 32.500 \\
\hline
\end{tabular}

Dari tabel 3 terlihat bahwa deductible sangat berpengaruh terhadap besarnya harga premium.

\section{KESIMPULAN}

Harga premium yang ideal berada pada kisaran harga Rp. 24.000-Rp. 60.000 per Ha. Harga premium asuransi yang ideal untuk tanaman Sagu di Kabupaten Luwu sangat bergantung pada besarnya deductible. Harga premium untuk deductible dengan range kecil menghasilkan harga yang relative lebih murah dibandingkan range deductible yang besar. 


\section{DAFTAR PUSTAKA}

Amblard, C. \& S. Girard. 2009. A New Extension of Bivariate FGM Copulas. Metrika, 70: 1-17.

Asmara, R., W. Widyawati \& A.H. Hidayat. 2019. Preferensi Resiko Petani Dalam Alokasi Input Usahatani Jagung Menggunakan Model Just and Pope. Jurnal Ekonomi Pertanian dan Agribisnis, 3(2): 449-459.

Badan Pusat Statistik. 2017. Statistik Indonesia dalam Infografis 2017. BPSStatistics Indonesia.

Badan Pusat Statistik Kabupaten Luwu. 2019. Kabupaten Luwu Dalam Angka. BPSStatistics of Luwu Regency.

Bekrizadeh, H., G.A. Parham \& M.R. Zadkarni. 2012. The New Generalization of Farlie-GumbleMorgenstern. Applied Mathematical Sciences, 6(71): 3527-3533.

Fisher N.I. 1997. Copulas In: Kotz S., Read CB, Banks DL (eds) Encyclopedia of Statistical Sciemces, 1(1): 159-163.
Multyaningsih, E. \& A. Nuryanto. 2014. Metodologi Penelitian Terapan Bidang Pendidikan. Alfabeta, Bandung.

Myung, I.J. 2003. Tutorial on Maximum Likelihood Estimation. Journal of Mathematical Psychology, 47(1): 90100.

Nelsen, R.B. 2006. An Introduction to Copulas (Second Edition). Springer, New York.

Pintari, H.O. \& R. Subekti. 2018. Penerapan Metode GARCH-Vine Copula untuk Estimasi Value at Risk (VaR) pada Portofolio. Jurnal Fourier, 7(2): 6377.

Zamzany, F.R. \& E. Setiawan. 2018. Reaksi Sinyal Keuangan Terhadap Harga Saham Sektor Pertanian di Indonesia. Jurnal Bisnis dan Manajemen, 8(2): 133-140. 